Click www.researchjournal.co.in/online/subdetail.html to purchase.

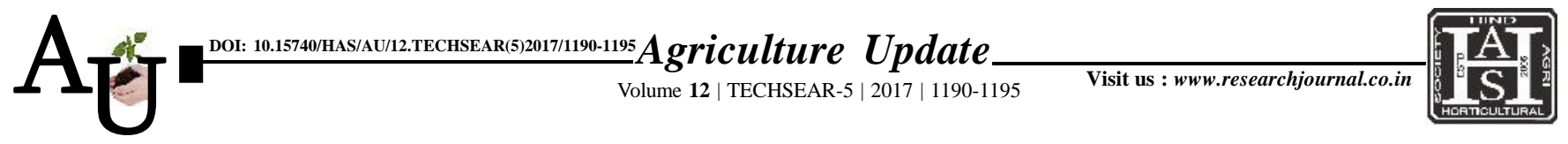

\title{
Research автіст: Biochemical characterization of Pseudomonas fluorescens against Alterneria alternata in ashwagandha
}

\section{N. KALIESWARI}

Article Chronicle : Received : 15.07.2017;

Accepted : 30.07.2017

KEY WoRDS:

Pseudomomas, Alternaria alternata, Ashwagandha, Biochemical, In vitro

Author for correspondence :

N. KALIESWARI Department of Plant Pathology, Vanavarayar Institute of Agriculture, Manakkadavu, POLLACHI (T.N.) INDIA Email : kalies.pat@ gmail.com
SUMMARY : A field survey was conducted from different ashwagandha growing areas of Tamil Nadu viz., Ottanchatram, Coimbatore, Periyakulam, Theni, Nilakottai, Chempatti, Palur, Vadipatti, Virudhunagar and Cumbum with a view to assess disease intensity. Ten isolates of Pseudomonas fluorescens were isolated from the rhizosphere soil. The effective isolates were also used as biocontrol agents. Among ten isolates were tested, three isolates of Pseudomonas fluorescens viz., Pf5, Pf1 and Pf4 were effectively identified by different biochemical methods viz., $\mathrm{KOH}$ test, anerobic growth, Arginine dehydrogenase starch hydrolysis, siderophore and $\mathrm{HCN}$ production. Among the four isolates tested for $\mathrm{HCN}$ production, the isolate $\mathrm{Pf}_{5}$ recorded as strong producer of $\mathrm{HCN}$ with $\mathrm{OD}$ value of 0.090 followed by isolate $\mathrm{Pf}_{1}(\mathrm{OD}$ value of 0.063 ). Based on these biochemical methods and characterization of the strains were identified as a gram negative Pseudomonas species. Among the ten isolates of Pseudomonas fluorescens were tested against $A$. alternata, $\mathrm{Pf}_{5}$ recorded the highest inhibition of mycelial growth of A. alternata over control by recording $61.71 \%$ inhibition. The lowest \% inhibition (22.86\%) of mycelial growth of $A$. alternata was recorded by $\mathrm{Pf}_{8}$.

How to cite this article : Kalieswari, N. (2017). Biochemical characterization of Pseudomonas fluorescens against Alterneria alternata in ashwagandha. Agric. Update, 12(TECHSEAR-5) : 1190-1195; DOI: 10.15740/ HAS/AU/12.TECHSEAR(5)2017/1190-1195. 